\title{
Lixiviação e volatilização de nitrogênio em um Argissolo cultivado com videira submetida à adubação nitrogenada
}

\author{
Lixiviation and volatilization of nitrogen in Sandy Typic Hapludalf soil cultivated with grapevine \\ submitted to the nitrogen fertilization
}

\author{
Felipe Lorensini $^{{ }^{*}}$ Carlos Alberto Ceretta ${ }^{\mathrm{II}}$ Eduardo Girotto ${ }^{\mathrm{I}}$ Jackson Berticelli Cerini ${ }^{\mathrm{I}}$ \\ Cledimar Rogério Lourenzi ${ }^{\mathrm{I}}$ Lessandro De Conti ${ }^{\mathrm{II}}$ Mateus Moreira Trindade \\ George Wellington de Melo ${ }^{\text {III }}$ Gustavo Brunetto ${ }^{\text {IV }}$
}

\section{RESUMO}

O nitrogênio (N) aplicado na superfície do solo em vinhedos pode ser perdido por volatilização ou lixiviação, sendo uma das possíveis explicações para o baixo aproveitamento de $N$ pelas videiras. $O$ trabalho objetivou avaliar as perdas de $\mathrm{N}$ por volatilização e lixiviação do $\mathrm{N}$ mineral em solo cultivado com videira submetida à adubação nitrogenada. Foram instalados dois experimentos em um vinhedo de Cabernet Sauvignon, em Rosário do Sul (RS), Brasil. No experimento 1, foram instalados lisímetros no solo que recebeu a aplicação de 0, 40, 80 e $120 \mathrm{~kg}_{\text {de }} \mathrm{N} \mathrm{ha}^{-1}$ ano $^{-1}$ na forma de ureia e, durante o período de agosto a dezembro de 2009, foi coletada a solução do solo para a análise de $N$ mineral. No experimento 2, foram instaladas câmaras coletoras no solo que recebeu, em agosto de 2010, a aplicação de 0, 20, 40, e

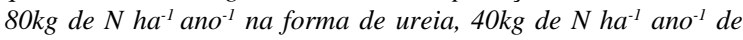
composto orgânico e $40 \mathrm{~kg}$ de $\mathrm{N} \mathrm{ha}^{-1}$ ano ${ }^{-1}$ de ureia revestida com polímeros, para avaliar a volatilização de $\mathrm{N}-\mathrm{NH}_{3}$ do momento da aplicação até 80 horas depois da aplicação. As maiores concentrações de nitrogênio mineral na solução lixiviada foram encontradas nas doses mais elevadas de fertilizante mineral aplicado e ao longo da brotação $e$ florescimento das videiras, o que pode diminuir o aproveitamento do nutriente pelas plantas. Os maiores fluxos e perdas de amônia do solo cultivado com videira para a atmosfera aconteceram nas doses mais elevadas de nitrogênio mineral aplicado, especialmente, depois de 44 horas da sua aplicação sobre a superfície do solo. A aplicação de ureia revestida com polímeros e composto orgânico promoveram as menores perdas de amônia por volatilização, o que pode estimular o aproveitamento de nitrogênio pelas videiras.

Palavras-chave: nitrogênio, nitrato, amônia, Vitis vinifera.

\begin{abstract}
Nitrogen $(N)$ applied in vineyards may be lost through volatilization or lixiviation. Two experiments were carried out to evaluate the $N$ losses through volatilization or lixiviation in vineyard submitted the $N$ fertilization, at Sandy Typic Hapludalf soil in Southern Brazil. In the experiment 1 , the treatments were applications of $0,40,80$ and $120 \mathrm{~kg} \mathrm{~N} \mathrm{ha}^{-1}$, as urea form, and analyze $N$ concentration in soil solution. The soil solution was collected by lysimeters during the cycle of the grapevines. In the experiment 2, the treatments were 0, 20, 40, and $80 \mathrm{~kg} \mathrm{~N} \mathrm{ha}^{-1}$, as urea form, $40 \mathrm{~kg} \mathrm{ha}^{-1} \mathrm{~N}$ as composed organic

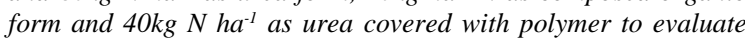
ammonia volatilization until 80 hours after $N$ fertilization. The largest concentration of mineral nitrogen were detected in the leach solution from treatments of higher doses of mineral fertilizer, along the budding and along the flowering of grapevines and this factors may decrease the nutrient efficiency. The largest flows and losses of ammonia to the atmosphere from a soil cultivated with grapevines happened at treatments with highest doses of mineral nitrogen. The highest lose happened 44 hours after fertilizer application on soil surface. The application of urea coated with polymers and organic compounds showed the smallest ammonia losses by volatilization, which may improve nitrogen efficiency by grapevines.
\end{abstract}

Key words: nitrogen, nitrate, ammonia, Vitis vinifera.

\section{INTRODUÇÃO}

No Estado do Rio Grande do Sul (RS), a partir da década de 80, os solos sob campo natural da

\footnotetext{
IPrograma de Pós-graduação em Ciência do Solo, Universidade Federal de Santa Maria (UFSM), 97105-900, Santa Maria, RS, Brasil. E-mail: felipe.lorensini@hotmail.com.*Autor para correspondência.

IIDepartamento de Solos, UFSM, Santa Maria, RS, Brasil.

"IIEmbrapa Uva e Vinho, Bento Gonçalves, RS, Brasil.

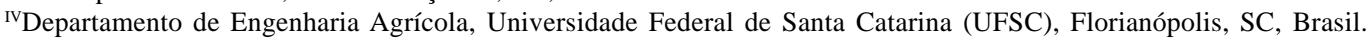


Campanha Gaúcha localizada no Sudeste foram incorporados ao sistema de produção de uvas. Os solos, na sua maioria, apresentam textura arenosa, baixo ou médio teor de matéria orgânica e, consequentemente, baixa capacidade de fornecimento de nitrogênio (N) (BRUNETTO, 2008). Com isso, esperase que o teor de $\mathrm{N}$ na folha completa seja abaixo do normal (<16 k kg ${ }^{-1}$ ) (CQFS-RS/SC, 2004), tornando-se necessária a aplicação de fertilizantes nitrogenados na videira.

O N em videiras é, normalmente, aplicado na superfície do solo, na linha de plantio e em faixas que coincidem com a projeção da copa das videiras, sem incorporação (CQFS-RS/SC, 2004). Entretanto, tem-se observado, com uso de ureia enriquecida com isótopos de ${ }^{15} \mathrm{~N}$, que as videiras aproveitam pequena quantidade de $\mathrm{N}$ do fertilizante aplicado (BRUNETTO, 2008). Isso tem sido atribuído em parte à lixiviação de $\mathrm{N}$ do fertilizante no perfil do solo na forma de nitrato (N$\mathrm{NO}_{3}{ }^{-}$) e até, possivelmente, mas em menor quantidade, de amônio $\left(\mathrm{N}_{-} \mathrm{NH}_{4}^{+}\right)$, fenômeno comum em pomares de frutíferas e provável em vinhedos (BARLOW et al., 2009). Porém, a quantidade de N lixiviada é dependente, especialmente, da quantidade do $\mathrm{N}$ aplicado, do tipo de solo e do volume de precipitação (NIELSEN et al., 1982).

O pequeno aproveitamento pela videira do $\mathrm{N}$ aplicado também pode estar associado à transferência do nutriente do solo para a atmosfera. Depois da aplicação de fontes de fertilizantes nitrogenados, na superfície do solo, elas são rapidamente hidrolisadas pelas enzimas extracelulares ureases, produzidas por microrganismos, como as bactérias, os actinomicetos e os fungos do solo. Com isso, é formado carbonato de amônio $\left(\mathrm{NH}_{4}^{+}\right)_{2} \mathrm{CO}_{3}$ que não é estável e se decompõe em amônia $\left(\mathrm{N}^{-} \mathrm{NH}_{3}\right), \mathrm{CO}_{2}$ e água. Assim, a $\mathrm{N}-\mathrm{NH}_{3}$ é emitida na forma de gás para a atmosfera, especialmente em maior intensidade, logo depois da aplicação do fertilizante (SANGOI et al., 2003). No entanto, a quantidade de $\mathrm{N}-\mathrm{NH}_{3}$ volatilizada é dependente, principalmente, das condições climáticas, como da velocidade do vento, da temperatura, da umidade relativa do ar e da precipitação; e de atributos do solo, como a capacidade de troca de cations, da umidade, da temperatura, da quantidade de matéria orgânica, do potencial de nitrificação, dos valores de $\mathrm{pH}$ e das

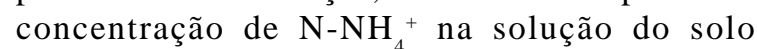
(ROCHETTE et al., 2009).

Como estratégia para minimizar a

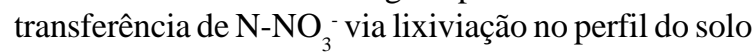
e de $\mathrm{N}-\mathrm{NH}_{3}$ pela volatilização têm sido utilizadas fontes orgânicas com liberação mais lenta de N, como os compostos orgânicos e fertilizantes nitrogenados minerais revestidos, como a ureia revestida, a partir dos quais talvez seja possível aumentar o sincronismo entre a liberação de $\mathrm{N}$ do fertilizante e a sua absorção pela planta, quando comparado com o uso de ureia (AZEVEDO et al., 2009). Os compostos orgânicos podem ser obtidos pela compostagem aeróbia de resíduos orgânicos, como as borras de suco, a serragem, entre outros resíduos do processo de vinificação. Já os fertilizantes minerais revestidos podem ser protegidos com alguns materiais, como os polímeros, em que é criada uma barreira física ao redor do grânulo do fertilizante, o que pode diminuir a velocidade de liberação do N, comparativamente aos fertilizantes não revestidos (MORGAN et al., 2009).

O presente trabalho objetivou avaliar a lixiviação de $\mathrm{N}$ mineral no perfil do solo submetido à aplicação de fertilizante nitrogenado mineral e cultivado com videira e a volatilização de $\mathrm{N}-\mathrm{NH}_{3}$ em solo adubado com fontes de $\mathrm{N}$ e cultivados com a videira.

\section{MATERIAL E MÉTODOS}

Foram conduzidos dois experimentos em um vinhedo de viníferas, no município de Rosário do Sul (RS), região da Campanha Gaúcha Central (latitude 30¹5' 26.75"S; longitude 5458’43.72"W) (datum WGS84). O clima da região é subtropical úmido, tipo Cfa 2 e o solo foi classificado como Argissolo Vermelho, apresentando, na camada de $0-20 \mathrm{~cm}$, antes da implantação dos experimentos: argila $70 \mathrm{~g} \mathrm{~kg}^{-1}$; matéria

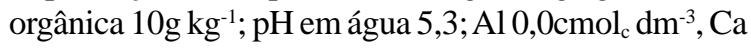
$0,9 \mathrm{cmol}_{\mathrm{C}} \mathrm{dm}^{-3}$ e $\mathrm{Mg} 0,6 \mathrm{cmol}_{\mathrm{c}} \mathrm{dm}^{-3}$ (ambos extraídos por $\mathrm{KCl} 1 \mathrm{~mol} \mathrm{~L}^{-1}$ ); P 30mg dm${ }^{-3}$ e $\mathrm{K} 48 \mathrm{mg} \mathrm{dm}^{-3}$ (ambos extraídos por Mehlich 1). A cultivar foi a 'Cabernet Sauvignon', enxertada sobre o porta-enxerto $\mathrm{SO}_{4}$, plantada na densidade de 3.704 plantas por hectare e sustentadas em sistema espaldeira.

No experimento 1, em agosto de 2008 e 2009, durante a brotação, as videiras foram submetidas à aplicação de 0 , 40, 80 e $120 \mathrm{~kg}$ de $\mathrm{N} \mathrm{ha}^{-1} \mathrm{ano}^{-1}$, totalizando, ao longo de dois anos, $0,80,160$ e $240 \mathrm{~kg}$ de $\mathrm{N} \mathrm{ha}^{-1}$. O N foi aplicado manualmente, na forma de ureia (45\% de $\mathrm{N}$ ), na superfície do solo, sem incorporação e em faixas de 0,5m de largura na projeção da copa, a partir do caule. O delineamento experimental usado foi blocos ao acaso com três repetições, sendo cada parcela formada por cinco plantas.

Em agosto de 2009, foram instalados lisímetros nas três plantas centrais de cada parcela, em todos os tratamentos, na profundidade de $20 \mathrm{~cm}$, na linha de plantio das videiras, onde anualmente o $\mathrm{N}$ foi aplicado, distantes, aproximadamente, $25 \mathrm{~cm}$ do caule de cada planta. Em 2009, nas datas de 01/09, 07/09, 11/ 09, 04/10, 09/10, 21/10, 29/10, 07/11, 16/12, 20/12 e 24/ 
12, correspondente aos eventos ocorridos a 10, 16, 20 , 43, 48, 60, 68, 77, 116, 120 e 124 dias após a aplicação do fertilizante, respectivamente, foi aplicado vácuo (25kgf), usando uma bomba manual e a solução do solo retida no interior dos lisímetros foi retirada com o auxílio de uma seringa acoplada a uma mangueira. Em seguida, nas amostras da solução do solo, foram determinados os teores de $\mathrm{N}-\mathrm{NH}_{4}{ }^{+}$e N-NO${ }_{3}^{-}$(TEDESCO et al., 1995).

Em março de 2010, logo após a colheita da uva, foi realizada a coleta do solo na camada de 0 $20 \mathrm{~cm}$, na linha de plantio ao lado das três plantas centrais de cada parcela, distantes, aproximadamente, $25 \mathrm{~cm}$ do caule de cada planta. Em seguida, o solo foi colocado em sacos plásticos, armazenado em caixas de isopor com gelo com temperatura de, aproximadamente, $4^{\circ} \mathrm{C}$ e conduzidos ao laboratório, onde foi preparado e submetido à análise de $\mathrm{N}-\mathrm{NH}_{4}{ }^{+}$e N-NO ${ }_{3}^{-}$(TEDESCO et al., 1995). Parte da amostra de cada solo foi utilizada para a determinação do teor de umidade, com isso os teores de $\mathrm{N}-\mathrm{NH}_{4}{ }^{+}$e $\mathrm{N}-\mathrm{NO}_{3}{ }^{-}$foram calculados em mg de $\mathrm{N}$ por $\mathrm{kg}^{-1}$ de solo seco.

No experimento 2, em agosto de 2010, nos tratamentos em que foram aplicadas as doses de 0,20 , 40 , e $80 \mathrm{~kg}$ de $\mathrm{N} \mathrm{ha}^{-1} \mathrm{ano}^{-1}$, na forma de ureia, do experimento 1, e em mais dois tratamentos: $40 \mathrm{~kg}$ de $\mathrm{N}$ $\mathrm{ha}^{-1} \mathrm{ano}^{-1}$ na forma de composto orgânico, como as seguintes características: matéria seca $841 \mathrm{~g} \mathrm{~kg}^{-1}$; $\mathrm{pH}$

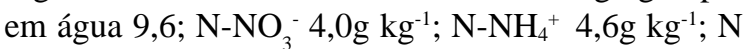
total $19,0 \mathrm{~g} \mathrm{~kg}^{-1}$; P total 17,3g kg-1 ; K total $32 \mathrm{~g} \mathrm{~kg}^{-1}$; Ca total $25 \mathrm{~g} \mathrm{~kg}^{-1}$; Mg total 2,0g kg-1 e carbono orgânico total 199,0 $\mathrm{g} \mathrm{kg}^{-1} \%$; e $40 \mathrm{~kg}$ de $\mathrm{N} \mathrm{ha}^{-1} \mathrm{ano}^{-1}$ na forma de ureia revestida com polímeros foram instaladas câmaras coletoras de $\mathrm{N}_{-} \mathrm{NH}_{3}$ do tipo semi-aberta (NÔMMIK, 1973). O N, na forma de ureia, dos tratamentos com aplicação de 0, 20, 40 e 80kg de $\mathrm{N} \mathrm{ha}^{-1} \mathrm{ano}^{-1}$ e com $40 \mathrm{~kg}$ de $\mathrm{N} \mathrm{ha}^{-1} \mathrm{ano}^{-1}$ na forma de composto orgânico foram aplicados nos meses de agosto de 2008, 2009 e 2010, o que coincidiu com a brotação das videiras. $\mathrm{O} N$ na forma de ureia revestida foi aplicado somente em agosto de 2010. O procedimento de aplicação de $\mathrm{N}$ foi o mesmo descrito no experimento 1 . O delineamento experimental foi blocos ao acaso com três repetições, sendo cada parcela formada por cinco plantas.

As câmaras coletoras de $\mathrm{N}-\mathrm{NH}_{3}$ foram instaladas na faixa de aplicação das fontes de $\mathrm{N}$, distantes, $35 \mathrm{~cm}$ das plantas. Elas foram construídas a partir de tubo de PVC (cloro-polivinil) de 300mm de diâmetro e 400mm de altura. Cada câmara foi assentada em uma base de PVC com 298mm de diâmetro e 50mm de altura, que foi introduzida no solo até uma profundidade de $30 \mathrm{~mm}$. Na superfície dos tubos, foi acoplada uma tampa protetora para impedir a incidência de raios solares no interior da câmara, bem como possíveis precipitações durante a coleta. Em cada câmara coletora foram colocados, sobre as estruturas metálicas, dois discos de espuma (tipo comercial) de $15 \mathrm{~mm}$ de espessura e com densidade de $28 \mathrm{~kg} \mathrm{~m}^{-3}$, saturadas com uma solução contendo $5 \%(\mathrm{v} / \mathrm{v})$ de $\mathrm{H}_{3} \mathrm{PO}_{4}$ e $4 \%$ (v/v) de glicerina. O primeiro disco de espuma foi instalado a uma altura de $150 \mathrm{~mm}$ do solo, para a captura do $\mathrm{N}-\mathrm{NH}_{3}$ volatilizado a partir do solo, e o segundo disco a 300mm de altura, para captar o N$\mathrm{NH}_{3}$ proveniente da atmosfera, impedindo a contaminação da esponja no primeiro disco.

Em agosto de 2010, após o período de 4, 8, 20, 32, 44, 56, 68 e 80 horas da aplicação das fontes de $\mathrm{N}$, os discos de espuma foram coletados e submetidos a dez lavagens sucessivas com a solução de $\mathrm{KCl} 1 \mathrm{~mol}$ $\mathrm{L}^{-1}$ para a extração do fosfato de amônio, sendo o volume final ajustado para $1000 \mathrm{~mL}$, com a mesma solução de $\mathrm{KCl} 1 \mathrm{~mol} \mathrm{~L}^{-1} \mathrm{e}$, posteriormente, uma alíquota de $20 \mathrm{~mL}$ foi submetida à análise de $\mathrm{N}^{-\mathrm{NH}_{4}^{+}}$(TEDESCO et al., 1995). A falta de "independência” entre as observações ao longo do período de avaliação e impossibilidade de se controlar experimentalmente algumas variáveis tais como o volume e o intervalo das precipitações implica a não satisfação de todos os pressupostos da análise de variância. Por isso, optouse por apresentar as médias dos resultados obtidos nos dois experimentos com seus respectivos desvios padrões.

\section{RESULTADOS E DISCUSSÃO}

No experimento 1, as maiores concentrações de $\mathrm{N}_{-} \mathrm{NO}_{3}^{-}$na solução do solo coletada na profundidade de $20 \mathrm{~cm}$ na linha de plantio das videiras tenderam a ser encontradas na dose de $120 \mathrm{~kg}$ de $\mathrm{N} \mathrm{ha}^{-1}$ ano $^{-1}$, especialmente, entre 20 e 77 dias após a aplicação dos fertilizantes (Figura 1a). Nesse mesmo período, as concentrações de $\mathrm{N}^{-\mathrm{NO}_{3}^{-}}$encontradas na solução do solo da dose $80 \mathrm{~kg}$ de $\mathrm{N}_{\text {ha }}{ }^{-1} \mathrm{ano}^{-1}$ tenderam a ser menores que as encontradas na dose de $120 \mathrm{~kg}$ de $\mathrm{N}$ $\mathrm{ha}^{-1} \mathrm{ano}^{-1}$, porém foram maiores que as da dose de $40 \mathrm{~kg}$ de $\mathrm{N} \mathrm{ha}^{-1} \mathrm{ano}^{-1}$. Com base nesses dados, pode-se inferir

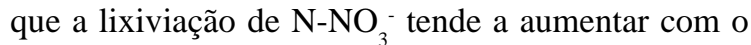
aumento da dose do fertilizante mineral, o que concorda com os dados obtidos por TASCA et al. (2011). Também se observa que as maiores transferências de $\mathrm{N}_{-} \mathrm{NO}_{3}^{-}$ no perfil do solo, observadas entre 20 e 77 dias, aconteceram ao longo da brotação das videiras, antecedendo o início do florescimento. Ou seja, parte do $\mathrm{N}$ aplicado via fertilizante mineral provavelmente não será aproveitado pelas videiras, uma vez que, parte do $\mathrm{N}_{-} \mathrm{NO}_{3}$ - foi encontrado na profundidade de $20 \mathrm{~cm}$ e, em geral, para a maioria das cultivares e porta-enxertos, 


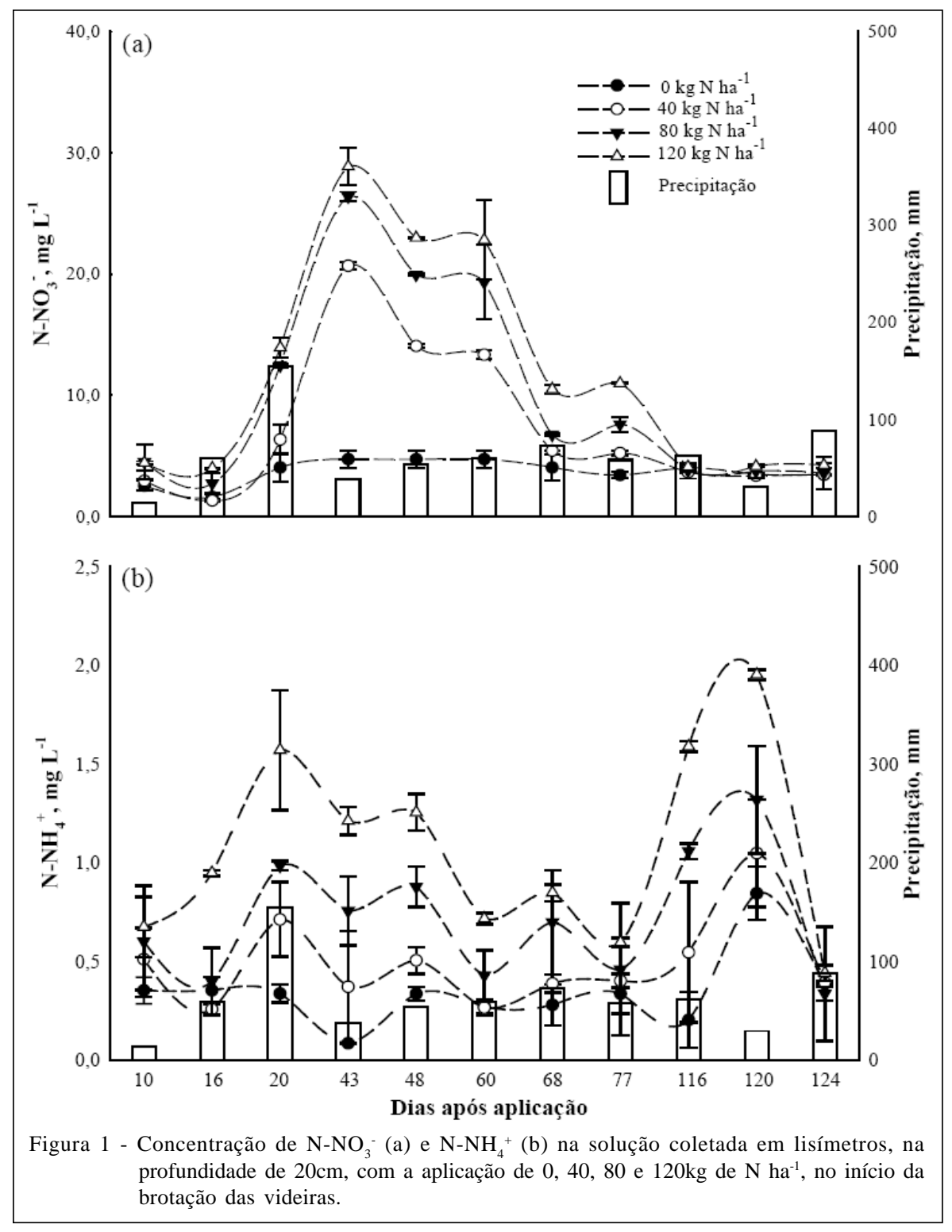

a maior parte das raízes finais responsáveis pela absorção de água e também nutrientes são localizadas em camadas mais superficiais do solo (SOARES \& NASCIMENTO, 1998). Essa pode ser uma das possíveis explicações para o pequeno aproveitamento pela Cabernet Sauvignon do N mineral derivado da ureia, quando aplicado na linha de plantio e sobre a superfície de um solo Argissolo Vermelho, encontrado por BRUNETTO(2008).

Nos eventos 116, 120 e 124 dias após a aplicação, a concentração de $\mathrm{N}-\mathrm{NO}_{3}{ }^{-}$encontrada na solução lixiviada do solo submetido à aplicação de 0 , 40, 80 e $120 \mathrm{~kg}$ de $\mathrm{N} \mathrm{ha}^{-1}$ ano $^{-1}$ foi similar (Figura 1a). Isso pode ser atribuído à lixiviação de $\mathrm{N}-\mathrm{NO}_{3}{ }^{-}$no perfil do solo nos períodos anteriores, mas também a maior absorção pela videira de formas de $\mathrm{N}$ do solo, inclusive o $\mathrm{N}-\mathrm{NO}_{3}{ }^{-}$, que pode também ser derivado do fertilizante aplicado, uma vez que esse período coincidiu com o florescimento, que é um dos estádios fenológicos de maior demanda de nutrientes pelas plantas (SCHREINER \& SCAGEL, 2006). No entanto, convém ressaltar que, nesses mesmos dias (116, 120 e 124), as concentrações de $\mathrm{N}_{-} \mathrm{NH}_{4}{ }^{+}$na solução do solo, mesmo sendo menores que as de $\mathrm{N}_{-} \mathrm{NO}_{3}{ }^{-}$(Figura 1a), em todos os tratamentos com a aplicação de ureia, tenderam a aumentar (Figura 1b).

Em todo período avaliado, as maiores concentrações de $\mathrm{N}-\mathrm{NH}_{4}{ }^{+}$na solução lixiviada no perfil do solo tenderam a ser encontradas no tratamento $120 \mathrm{~kg}$ de $\mathrm{N} \mathrm{ha}^{-1} \mathrm{ano}^{-1}$ (Figura $1 \mathrm{~b}$ ), similar ao observado 
com a lixiviação de $\mathrm{N}_{-} \mathrm{NO}_{3}^{-}$(Figura 1a). Nesse período, a concentração de $\mathrm{N}-\mathrm{NH}_{4}{ }^{+}$na solução do solo submetido à aplicação de $80 \mathrm{~kg}$ de $\mathrm{N} \mathrm{ha}^{-1}$ ano $^{-1}$ foi menor que a obtida na dose de $120 \mathrm{~kg}$ de $\mathrm{N} \mathrm{ha}^{-1}$ ano $^{-1}$, porém foi maior que as encontradas na solução do solo lixiviada, coletada no solo submetido à aplicação de $40 \mathrm{~kg}$ de $\mathrm{N} \mathrm{ha}^{-1} \mathrm{ano}^{-1}$.

Os teores de $\mathrm{N}$ mineral no solo, na camada de $20 \mathrm{~cm}$, na linha de plantio das videiras e logo depois da colheita da uva aumentaram de forma quadrática $\left(y=1,13+0,004 x+0,0004 x^{2}, r^{2}=0,98\right)$ com a dose de $N$ aplicada $\left(0,40,80\right.$ e $120 \mathrm{~kg}$ de $\left.\mathrm{N} \mathrm{ha}^{-1} \mathrm{ano}^{-1}\right)$ no início da brotação. No entanto, esse aumento foi pequeno, 1,28mg de $\mathrm{N} \mathrm{kg}^{-1}$ na testemunha e 7,32mg de $\mathrm{N} \mathrm{kg}^{-1}$ no tratamento com aplicação de $120 \mathrm{~kg}$ de $\mathrm{N} \mathrm{ha}^{-1}$ ano $^{-1}$.

No experimento 2, o fluxo de emissão de $\mathrm{N}$ $\mathrm{NH}_{3}\left(\mathrm{mg} \mathrm{ha}^{-1} \mathrm{~h}^{-1}\right)$ foi similar nas doses 0,20 , 40 e $80 \mathrm{~kg}$ de $\mathrm{Nha}^{-1} \mathrm{ano}^{-1}$ em 4 e 8 horas depois da aplicação do $\mathrm{N}$ mineral na superfície do solo (Figura 2a). No entanto, a partir de 20 horas após a aplicação das doses de $\mathrm{N}$, o fluxo de emissão de $\mathrm{N}-\mathrm{NH}_{3}$ tendeu a ser maior na dose de $80 \mathrm{~kg}$ de $\mathrm{Nha}^{-1} \mathrm{ano}^{-1}$, comparativamente, a dose 0,20 e $40 \mathrm{~kg}$ de $\mathrm{N} \mathrm{ha}^{-1} \mathrm{ano}^{-1}$, sendo em 56 , 68 e 80 horas depois da aplicação do $\mathrm{N}$, verificados os maiores picos de emissão, que foram correspondentes a, 211,97; 211,35 e $217,20 \mathrm{mg}$ de $\mathrm{N} \mathrm{ha}^{-1} \mathrm{~h}^{-1}$, respectivamente. No período de 44 até 80 horas da aplicação do $\mathrm{N}$, a emissão de $\mathrm{N}$ $\mathrm{NH}_{3}$ na dose de $40 \mathrm{~kg}$ de $\mathrm{N} \mathrm{ha}^{-1}$ foi menor que a observada na dose de $80 \mathrm{~kg}_{\text {de }} \mathrm{Nha}^{-1}$, porém maior que a encontrada na dose de $20 \mathrm{~kg}$ de $\mathrm{Nha}^{-1}$.

A maior emissão de $\mathrm{N}-\mathrm{NH}_{3}\left(217,20 \mathrm{mg} \mathrm{ha}^{-1} \mathrm{~h}^{-1}\right)$ do solo para atmosfera, o que se reflete na sua quantidade perdida $\left(\mathrm{kg} \mathrm{ha}^{-1}\right)$, em doses maiores de $\mathrm{N}$ aplicadas na superfície do solo, como $80 \mathrm{~kg}$ de $\mathrm{N} \mathrm{ha}^{-1}$ (Figura 2c), pode ser atribuído à maior quantidade $\mathrm{e}$ sobreposição de grânulos do fertilizante nitrogenado aplicado, comparativamente as menores doses, como 20 e $40 \mathrm{~kg}$ de $\mathrm{Nha}^{-1} \mathrm{ano}^{-1}$. Com isso, nas maiores doses de $\mathrm{N}$ aplicadas, esperam-se reações de dissolução com maior elevação do valor de $\mathrm{pH}$ do sítio, favorecendo a formação e, por consequência, a emissão de $\mathrm{N}-\mathrm{NH}_{3}$ (VILLAS BOAS et al., 2005). Essa emissão pode colaborar para diminuir o aproveitamento pela videira do $\mathrm{N}$ aplicado na forma de fertilizante mineral e sobre a superfície do solo (CANTARELLA et al., 2003). De acordo com BRUNETTO (2008), aplicando 21,42kg de $\mathrm{N}$ ha ${ }^{-1}$ na forma de ureia marcada com ${ }^{15} \mathrm{~N}$, durante a brotação de Cabernet Sauvignon, cultivadas em um Argissolo Vermelho, na mesma região do presente trabalho, as plantas aproveitaram $5,12 \mathrm{~kg} \mathrm{ha}^{-1}$ do $\mathrm{N}$ aplicado, sendo detectado, na camada de $0-40 \mathrm{~cm}$ do solo, 3,85kg ha-1 de $\mathrm{N}$ do fertilizante. Assim, a quantidade aproveitada pelas plantas e detectada no solo totalizou $8,97 \mathrm{~kg}$ de $\mathrm{N} \mathrm{ha}^{-1}$, correspondendo a $41,82 \%$ do N aplicado.

O fluxo de emissão de $\mathrm{N}-\mathrm{NH}_{3}$, em 4 e 8 horas depois da aplicação de $40 \mathrm{~kg}$ de $\mathrm{N} \mathrm{ha}^{-1}$ na forma de ureia, ureia revestida e composto orgânico, foi similar entre as fontes (Figura 2b). A partir de 20 horas após a aplicação das fontes de $\mathrm{N}$, o fluxo de emissão de N$\mathrm{NH}_{3}$ tendeu a ser maior na fonte ureia e ureia revestida, comparativamente ao composto orgânico, que apresentou emissão de $\mathrm{N}-\mathrm{NH}_{3}$ similar ao tratamento testemunha. Já, no período de 56 até 80 horas após a aplicação das fontes de $\mathrm{N}$, as maiores emissões de $\mathrm{N}$ $\mathrm{NH}_{3}$ foram encontradas quando da aplicação de ureia. Nesse mesmo período, as emissões de $\mathrm{N}-\mathrm{NH}_{3}$ com a aplicação de ureia revestida foram menores que as encontradas no tratamento ureia, porém maiores que as observadas com a aplicação de composto orgânico. Convém destacar que o fluxo de emissão de $\mathrm{N}^{-} \mathrm{NH}_{3}$ com a aplicação de $40 \mathrm{~kg}$ de $\mathrm{N} \mathrm{ha}^{-1} \mathrm{ano}^{-1}$ na forma de ureia revestida com polímeros e composto orgânico é menos sensível às variações de umidade e temperatura do ambiente, comparativamente à aplicação de $40 \mathrm{~kg}$ de $\mathrm{N} \mathrm{ha}^{-1} \mathrm{ano}^{-1}$ na forma de ureia (Figura $2 \mathrm{~b}$ ).

As maiores perdas acumuladas de $\mathrm{N}-\mathrm{NH}_{3}$ $\left(\mathrm{kg} \mathrm{ha}^{-1}\right.$ ), depois de 80 horas da aplicação das fontes de $\mathrm{N}$, foram encontradas com a aplicação de $40 \mathrm{~kg}$ de $\mathrm{N}$ ha $^{-1}$ ano $^{-1}$ na forma de ureia (Figura 2d), comparativamente à aplicação de ureia revestida e composto orgânico. Assim, em 80 horas depois da aplicação de $40 \mathrm{~kg}$ de $\mathrm{N} \mathrm{ha}^{-1}$ ano $^{-1}$ na forma de ureia, ureia revestida e composto orgânico, as perdas acumuladas foram de 5,51; 3,39 e 0,35kg de $\mathrm{N} \mathrm{ha}^{-1}$, respectivamente. Os menores fluxos de emissão de $\mathrm{N}$ $\mathrm{NH}_{3}\left(\mathrm{mg} \mathrm{ha}{ }^{-1} \mathrm{~h}^{-1}\right)$ e, por consequência, as suas perdas $\left(\mathrm{kg} \mathrm{ha}^{-1}\right)$, quando aplicado o $\mathrm{N}$ na forma de ureia revestida, pode ser atribuído à difusão mais lenta do $\mathrm{N}$ contido no seu grânulo. Isso ocorre porque o grânulo da ureia é revestido por uma camada de polímeros. Por causa disso, espera-se um melhor sincronismo entre a liberação do $\mathrm{N}$ contido no grânulo e a absorção do nutriente pela videira, o que pode aumentar o aproveitamento pela planta do $\mathrm{N}$ aplicado (PEREIRA et al., 2009).

As baixas emissões de $\mathrm{N}-\mathrm{NH}_{3}$ no solo submetido à aplicação de $40 \mathrm{~kg}$ de $\mathrm{N} \mathrm{ha}^{-1} \mathrm{ano}^{-1}$ na forma de composto orgânico, comparativamente, á aplicação de ureia e ureia revestida com polímeros, especialmente depois de 56 horas da sua aplicação, pode ser explicada pela menor área de contato do composto com a superfície do solo, o que retarda a sua decomposição e, por consequência, a liberação de N (NENDEL et al., 2007), mas a quantidade de $\mathrm{N}$ liberada talvez não seja suficiente para suprir a demanda da planta pelo nutriente. 


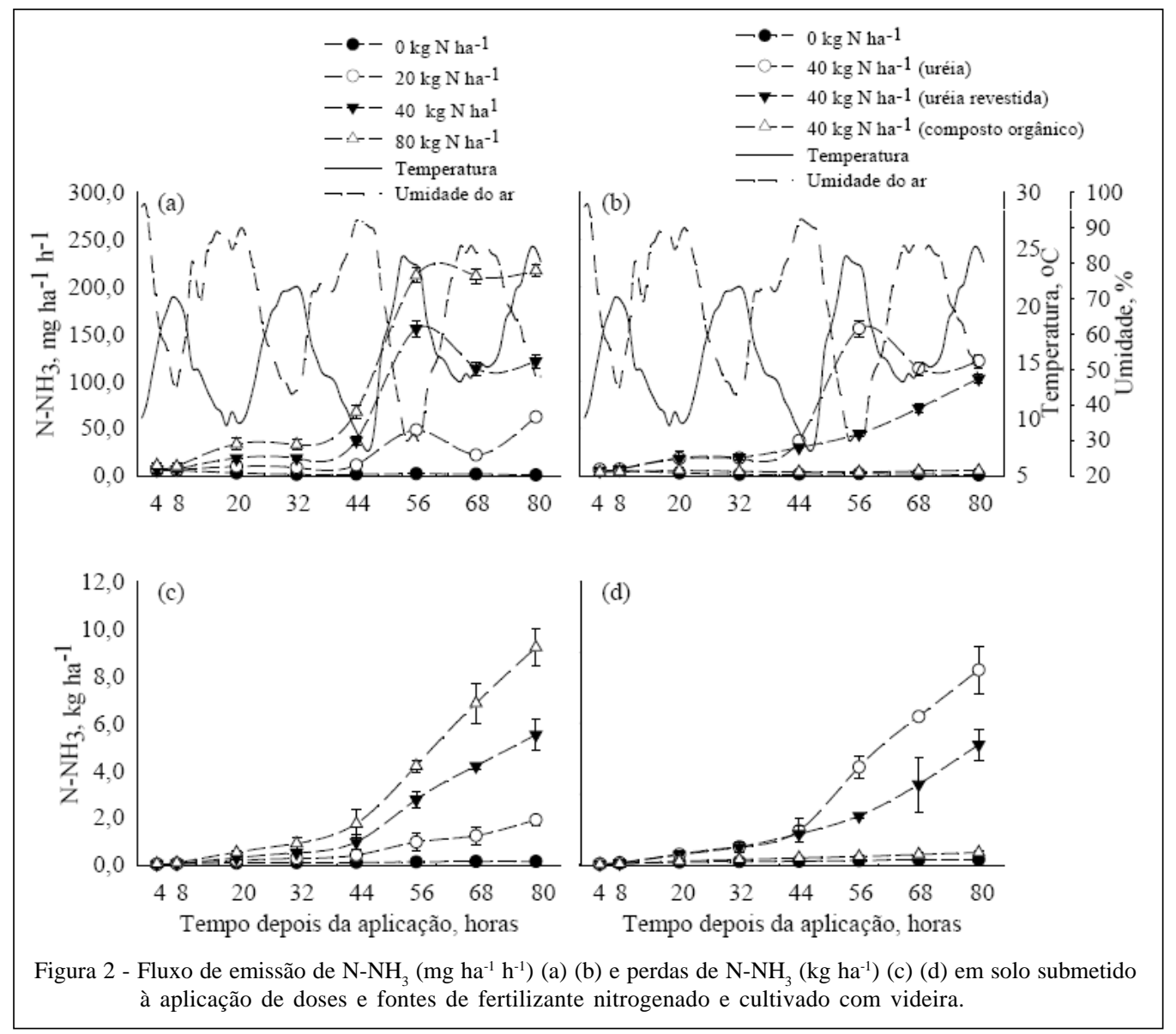

\section{CONCLUSÃO}

As maiores concentrações de nitrogênio mineral na solução lixiviada foram encontradas nas doses mais elevadas de fertilizante mineral aplicado e ao longo da brotação e florescimento das videiras, o que pode diminuir o aproveitamento do nutriente pelas plantas. Os maiores fluxos e perdas de amônia do solo cultivado com videira para a atmosfera aconteceram nas doses mais elevadas de nitrogênio mineral aplicado, especialmente, depois de 44 horas da sua aplicação sobre a superfície do solo. A aplicação de ureia revestida com polímeros e composto orgânico promoveu as menores perdas de amônia por volatilização, o que pode estimular o aproveitamento de nitrogênio pelas videiras.

\section{AGRADECIMENTOS}

Ao Conselho Nacional de Desenvolvimento Científico e Tecnológico (CNPq).

\section{REFERÊNCIAS}

AZEVEDO, E. B. et al. Substratos fertilizados com ureia revestida e o crescimento e estado nutricional da muda de citros. Acta Scientiarum Agronomy, v.31, n.1, p.129-137, 2009.

BARLOW, K. et al. Nitrogen concentrations in soil solution and surface run-off on irrigated vineyards in Austrália. Australian Journal of Grape and Wine Research, v.15, p.131-143, 2009. Disponível em: <http://www.blackwellsynergy.com/loi/ajgw>. Acesso em: 25 fev. 2011. doi: 10.1111/ j.1755-0238.2008.00042.x.

BRUNETTO, G. Nitrogênio em videira: recuperação, acumulação e alterações na produtividade e na composição da uva. 2008. 139f. Tese (Doutorado em Ciência do Solo) - Programa de Pós-graduação em Ciência do Solo, Universidade Federal de Santa Maria, Santa Maria, RS.

CANTARELLA, H. et al. Fruit yield of Valencia sweet orange fertilized with different $\mathrm{N}$ sources and the loss of applied $\mathrm{N}$. Nutrient Cycling in Agroecosystems, v.67, p.215-223, 2003. Disponivel em: <http://www.springerlink.com/content/ h36716770r596446/>. Acesso em: 28 fev 2011. doi: 10.1023/ B:FRES.0000003600.20499.76.

COMISSÃO DE QUÍMICA E FERTILIDADE DO SOLO - RS/ SC. Manual de adubação e calagem para os Estados do

Ciência Rural, v.42, n.7, jul, 2012. 
Rio Grande do Sul e de Santa Catarina. 10.ed. Porto Alegre: SBCS - Núcleo Regional Sul/UFRGS, 2004. 400p.

MORGAN, K. T. et al. Release mechanisms for solw- and controlled-release fertilizers and strategies for their use in vegetable production. Hortechnology, v.19, n.1, p.10-12, 2009.

NIELSEN, D. R. et al. Nitrogen transport process insoil. In: STEVENSON, P. J. (Ed.). Nitrogen in agriculture soils Madison: American Society of Agronomy, 1982. p.423-448.

NENDEL, C. et al. Nitrogen mineralization from mature biowaste compost in vineyard soils III Simulation of soil mineralnitrogen dynamics. Journal Plant Nutrition. Soil Science, v.170, p.598-607, 2007.

NÔMMIK, H. The effect of pellet size on the ammonia loss from urea applied to forest soil. Plant and Soil, v.39, n.2 p.309-318, 1973.

PEREIRA, H. S. et al. Ammonia volatilization of urea in the out-of-season corn. Revista Brasileira de Ciência do Solo, v.33, p.1685-1694, 2009. Disponível em: <http:/www.scielo.br/ pdf/rbcs/v33n6/a17v33n6.pdf>. Acesso em: 21 jan. 2011.

ROCHETTE, P. et al. Reducing ammonia volatilization in a no-till soil by incorporating urea and pig slurry in shallow bands. Nutrient Cycling in Agroecosystems, n.84, p.71-80, 2009.

SANGOI, L. et tal. Volatilização de N-NH em decorrência da forma de aplicação de ureia, manejo de resî̉duos e tipo de solo, em laboratório. Ciência Rural, v.33, n.4, p.687-692, 2003. Disponível em: <http://www.scielo.br/pdf/cr/v33n4/16690.pdf>. Acesso em: 12 mar. 2011

SCHREINER, R. P.; SCAGEL, C. F. Nutrient uptake and distribution in a mature 'Pinot Noir' vineyard. HortScience, v.41, p.336-345, 2006.

SOARES, J. M.; NASCIMENTO, T. Distribuição do sistema radicular da videira em vertissolo sob irrigação localizada. Revista Brasileira de Engenharia Agrícola e Ambiental, v.2, n.2, p.142-147, 1998. Disponível em: <http:// www.agriambi.com.br/revista/v2n2/142.pdf >. Acesso em: 13 mar. 2011

TASCA, F. A. et al. Volatilização de amônia do solo após a aplicação de ureia convencional ou com inibidor de urease. Revista Brasileira de Ciência do Solo, v.35, p.493-502, 2011.

TEDESCO, M.J. et al. Análises de solos, plantas e outros materiais. 2.ed. Porto Alegre: Departamento de Solos da Faculdade de Agronomia, UFRGS, 1995. 174p. (Boletim Técnico, 5).

VILLAS BOAS, R. L. et al. Nitrogen recovery of urea Ammonium sulphate mixtures by corn plants. Bragantia, v.64, n.2, p.263-272, 2005 . Disponível em: <http:// redalyc.uaemex.mx/pdf/908/90864214.pdf > . Acesso em: 25 abr. 2011. 